\title{
A atuação das mulheres fotógrafas no fotojornalismo brasileiro em 1970
}

\author{
Arlane Gomes Marinho' \\ DOI 10.20396/eha.vil4.3428
}

O Brasil dos anos de 1970 não foi marcado apenas pela censura militar, mas também pelo fortalecimento da segunda onda movimento feminista ${ }^{2}$ brasileiro, que surge nesta conjuntura como um ato também de resistência. Diferente do norte-americano e europeu, por conta do contexto político autoritário que o país enfrentava. No Brasil, o movimento teve sua origem dentro da classe média culta. Lutava-se pela liberdade da mulher, contra a censura e pela redução das desigualdades de gênero. Obviamente, que os mais conservadores e os militares que estavam no poder, não viam com bons olhos o movimento, julgando-o "subversivo", fato que impulsionou a ideia de reunirem-se às "escondidas".

As pautas abordadas pelas feministas brasileiras desta conjuntura estavam comprometidas com a luta pela redemocratização do país. Enquanto na Europa e nos Estados Unidos da América o cenário político era favorável ao desenvolvimento dos movimentos sociais de caráter libertário, na América do Sul, particularmente no Brasil a realidade era bem diferente. A investigadora Cynthia Sarti esclarece:

[...] o início do feminismo brasileiro dos anos 1970 foi significativamente marcado pela contestação à ordem política instituída no país, desde o golpe militar de 1964. Uma parte expressiva dos grupos feministas estava articulada a organização de influência marxista, clandestina à época, e fortemente comprometida com a oposição à ditadura militar, o que imprimiu ao movimento características próprias ${ }^{3}$.

Conectado ao movimento feminista e aos grupos de esquerda dentro deste contexto, de-

\footnotetext{
1 Universidade Federal do Espírito Santo. Mestranda do Programa de Pós-Graduação em Artes. Bolsista CAPES.

2 [...] a chamada primeira onda do feminismo aconteceu a partir das últimas décadas do século XIX, quando as mulheres, primeiro na Inglaterra, organizaram-se para lutar por seus direitos, sendo que o primeiro deles que se popularizou foi o direito ao voto. As sufragetes, como ficaram conhecidas, promoveram grandes manifestações em Londres, foram presas várias vezes, fizeram greves de fome. Em 1913, na famosa corrida de cavalo em Derby, a feminista Emily Davison atirou-se à frente do cavalo do Rei, morrendo. O direito ao voto foi conquistado no Reino Unido em 1918. (PINTO, 2010, p.15). No Brasil, a primeira onda do feminismo aconteceu posteriormente ao período europeu e foi liderado inicialmente por detentoras de títulos universitários e pertencentes à classe média. No entanto, perceberam a necessidade de agregar à agenda as necessidades daquelas de classes manos favorecidas, conseguindo influenciar também as mulheres das classes trabalhadoras. Uma das pautas de maior interesse era obter o direito ao voto, adquirido em 1932. A luta nesse momento era por diretos políticos.

3 SARTI, Cyntia Andersen. O feminismo brasileiro desde os anos 1970: revisitando uma trajetória. Estudos Feministas, Florianópolis, maio-agosto/2004, p. 34. Disponível em:<http://www.scielo.br/pdf/ref/v12n2/23959.pdf> Acesso em: 6 de março de 2019.
} 
senvolveu-se a imprensa alternativa - também chamada de imprensa nanica. Revelando-se de extrema relevância para a atuação e o posicionamento político dos grupos de resistência durante a barbárie ditatorial. Araújo 4 afirma que durante os anos de 1970 esses impressos possuíam formatos de tabloide ou minitabloide, e as tiragens eram irregulares; podiam ser comercializados em bancas ou não, o ponto em comum entre eles era o tom de oposição. Em um momento no qual a censura prévia à imprensa convencional era uma realidade, a alternativa apontou os atos desumanos dos ditadores e problematizou o autoritarismo.

Quanto ao conteúdo, o jornalista Bernardo Kucinski5 afirma que os periódicos alternativos denunciavam intensivamente os atos de tortura, os abusos aos direitos humanos, além de criticar publicamente o modelo econômico tão enaltecido pelos militares na época. Para o autor, o discurso destes jornais desafiava e discordava das informações vinculadas nos grandes impressos consagrados que circulavam no país. Caracterizando um ato de resistência e oposição "ao discurso oficial". O autor esclarece que a imprensa nanica foi um ambiente que possibilitou a "reorganização política e ideológica das esquerdas nas condições específicas do autoritarismo".

Nos jornais alternativos de esquerda, a presença de fotógrafas era muito reduzida se comparada ao número de fotógrafos e era mais comum elas realizarem trabalhos como freelancer para esses boletins. Nos periódicos alternativos feministas havia muitas mulheres na organização e na redação, mas na produção das fotorreportagens a quantidade era reduzida. No entanto, foi no âmbito desses espaços públicos alternativos de esquerda que muitas fotojornalistas encontraram liberdade de atuação, mesmo existindo em alguns momentos choques de convicções.

Alvira Alegre foi uma das poucos fotojornalistas a laborar para a mídia alternativa de esquerda. A única pessoa a fotografar o velório e o enterro do jornalista Vladimir Herzog, torturado até morrer nas dependências do DOI-CODI/SP em 1975. A fotojornalista trabalhava para o jornal EX-, pertencente à imprensa nanica. O periódico nasceu em 1973, possuía um tom jocoso e carregado de humor ácido em suas reportagens. A edição 16 do EX-noticiou em primeira mão a morte de Herzog, mas a reportagem foi para as bancas sem nenhuma foto daquelas capturadas por Alegre. Mesmo assim, foi necessário sair uma edição extra, pois todos os exemplares da primeira foram vendidos ${ }^{6}$.

As imagens não foram publicadas junto com a reportagem por falta de tempo para adicioná

\footnotetext{
4 ARAÚJO, Maria Paula Nascimento. A utopia fragmentada: as novas esquerdas no Brasil e no mundo na década de 1970. Rio de Janeiro: Ed. FGV, 2000

5 KUCINSKI, Bernardo. Jornalistas e revolucionários nos tempos da imprensa alternativa. São Paulo: Scritta, 1991, p. XIII.

6 INSTITUTO VLADIMIR HERZOG. Edição fac-similar do jornal Ex realizada nas oficinas gráficas da Imprensa Oficial do Estado de São Paulo. 2010.
} 
-las à edição, mas a fotojornalista relata também outro motivo que possivelmente influenciou tal decisão: "o Ex-com a matéria sobre a morte de Herzog, sem passar pela censura, foi para as bancas sem minhas fotos. Cheguei a ampliar algumas, mas o pessoal tinha pressa, e por isso não usaram" 7 . Tal edição do periódico não passou pela censura prévia. Prevendo a destruição que os militares iram fazer na Redação do jornal após a publicação, os funcionários abandonaram o local. A fotojornalista preservou todos os negativos e as fotografias ampliadas temendo o seu extermínio pelos órgãos de repressão.

As fotos só foram publicadas 1985 no jornal Folha de São Paulo, pois assim como Alegre, o jornalista Dácio Nitrini havia guardado algumas imagens das que a fotojornalista tinha ampliado na época. Divulgar essas imagens ao povo brasileiro, depois de uma década, se configura como o que o filósofo francês Ceorges Didi-Huberman ${ }^{8}$ chama de "restituir alguma coisa à esfera pública". No caso das fotos de Alegre a restituição à comunidade possibilitou o conhecimento de um episódio importante da história do país. Para o autor é necessário devolver as imagens censuradas para sociedade, com o intuito de “retorná-las a quem é de direito, quer dizer, ao 'público', à comunidade, aos cidadãos". Didi-Hurberman acredita, ainda, que as imagens proibidas de circular em espaços públicos são justamente aquelas necessárias a torna a história evidente e verdadeira, considerando que as mesmas pertencem ao patrimônio comum e não ao privado.

A fotojornalista afirma que a imagem de Audálio Dantas (figura 01) representa a impotência diante de tamanho absurdo. Uma das fotografias mais reconhecidas deste trabalho de Alegre traduz o sentimento de perda de um amigo, além de revelar ainda a aparente perda do desejar lutar por um país que garantisse o direito de ir e vir, de questionar, de refletir criticamente sobre sua realidade social e política. Pode-se ainda refletir sobre o exato momento que a fotojornalista registra Dantas escondendo a face o com as mãos (figura 01), talvez numa tentativa falida de esconder a própria identidade ou sentimento de derrota diante do inimigo monstruoso, que além de aniquilar a vida de um amigo, extinguiu também a esperança de continuar acreditando em dias melhores.

A tortura não machucava apenas o corpo do torturado, mas também a alma daqueles que o amavam. A filósofa Marilena Chaui a afirma que "a resistência é um esforço gigantesco para não perder a lucidez, não permitindo que o torturador penetre na alma, no espírito, na inteligência do torturado." Apesar de Chaui se referir ao empenho do sofredor em se manter firme psicologicamente,

\footnotetext{
7 Idem.

8 DIDI-HUBERMAN, Georges. Devolver uma imagem. In: ALLOA, Emmanuel (Org.). Pensar a imagem. Belo Horizonte: Autêntica, 2015, p. 206.

9 CHAUI, Marilena. Sobre a violência. Ericka Marie Itokazu, Luciana Chaui-Berlinck. (Orgs). Belo Horizonte: Autentica Editora. 2017, p. 134.
} 
sabemos que esse esforço está também presente no estado emocional dos parentes mais próximos desse indivíduo. Na fotografia (figura 02) de Alegre percebemos o registro da perda dessa lucidez diante da morte de um marido e um pai. Os olhos cerrados da viúva e ao mesmo tempo a mão que acarinha um dos filhos, revela o misto de dor e de força. Alento necessário para uma mãe que terá que seguir firme diante dos filhos.

Uma mulher que tem coragem para capturar por meio de suas lentes o sofrimento e a dor de outra mulher em pleno auge da repressão e da censura, com o risco de ser presa e torturada, se instituiu como ato de resistência e de coragem. Talvez, naquela situação a fotojornalista era a única que estava praticando um esforço gigante para manter sua sensatez diante de tamanha barbárie.

O processo de registro da fotojornalista aconteceu clandestinamente e sob o calor da emoção, tanto por não ter autorização dos militares para fotografar quanto pelo momento doloroso propriamente dito. Além disso, a reportagem foi para as bancas sem passar pela repreensão dos militares. Driblou duplamente a repressão militar. Alegre denunciou de forma subliminar não só a despedida de um jornalista, mas o adeus de uma voz ativa.

A fotojornalista Rosa Gauditano também teve uma atuação relevante na imprensa nanica. Ela começou a trabalhar como fotógrafa e depois como editora de fotografia para o jornal Versus, entre 1977 e 1980. Neste mesmo período, laborou como freelancer para outros periódicos alternativos, como o Movimento e Em Tempo. Os ensaios de Gauditano buscavam predominantemente documentar e visibilizar a realidade dos operários em greve durante o regime repressor, os movimentos de mulheres, dentre outros movimentos sociais que necessitavam de fortalecimento.

Em 1978 ela foi designada para fotografar as mobilizações que impulsionaram as greves do

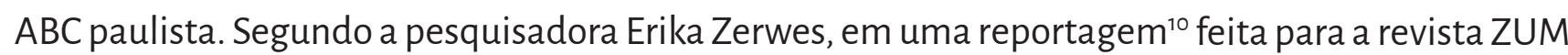
em 2018, afirma que Gauditano possuía bastante autonomia no processo fotográfico, pois realizava sua "própria pauta, escolhendo o que e como fotografar, revelava e ampliava as fotografias em sua própria casa, editava e depois as oferecia para os jornais alternativos".

Gauditano ressaltou em suas imagens, os movimentos sociais, e as más condições de trabalho, operários em greve por melhores salários. As lentes dela possibilitaram visibilizar a triste realidade social que sentiam na pele os trabalhadores e que não era discutida nos grandes veículos de comunicação. 


\section{[Figura 01]}

Alvira Alegre. O jornalista e escritor

Audálio Dantas chora ao lado do caixão do jornalista Vladimir Herzog.

1975.

Fonte: Acervo do Instituto Vladimir Herzog.

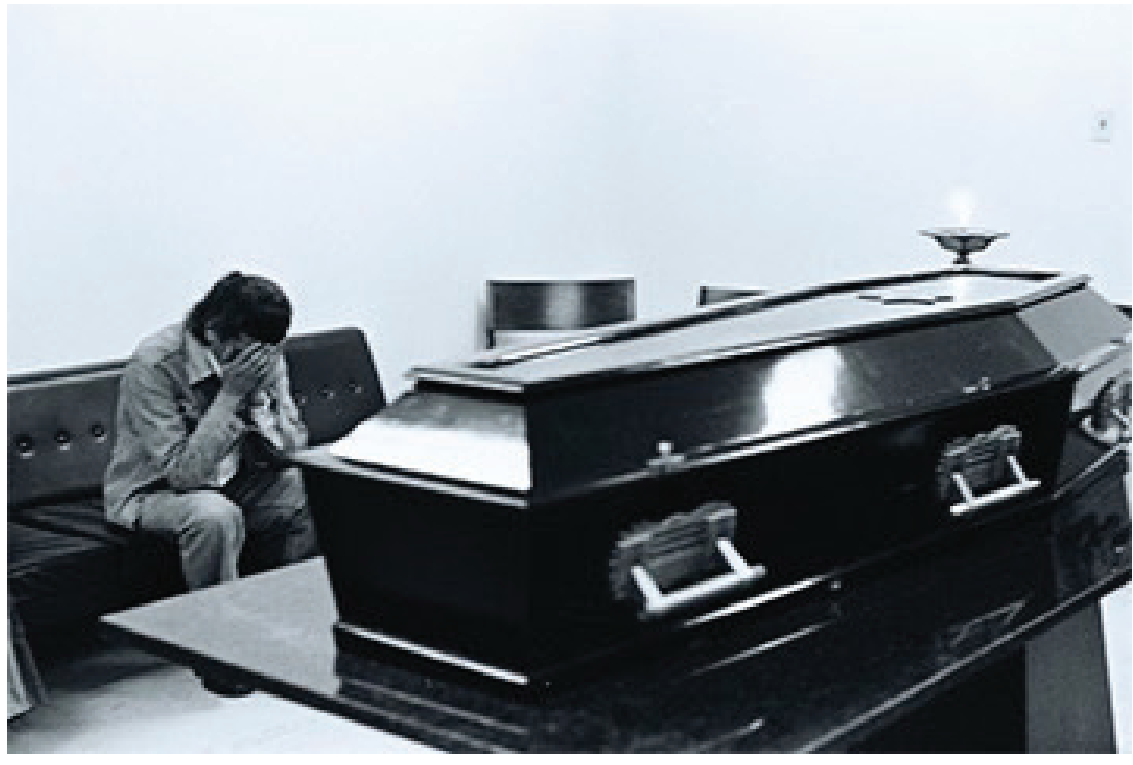

[Figura 02]

Alvira Alegre. Clarice, mulher de Vlado e seus filhos. 1975.

Fonte: Acervo do Instituto Vladimir Herzog.

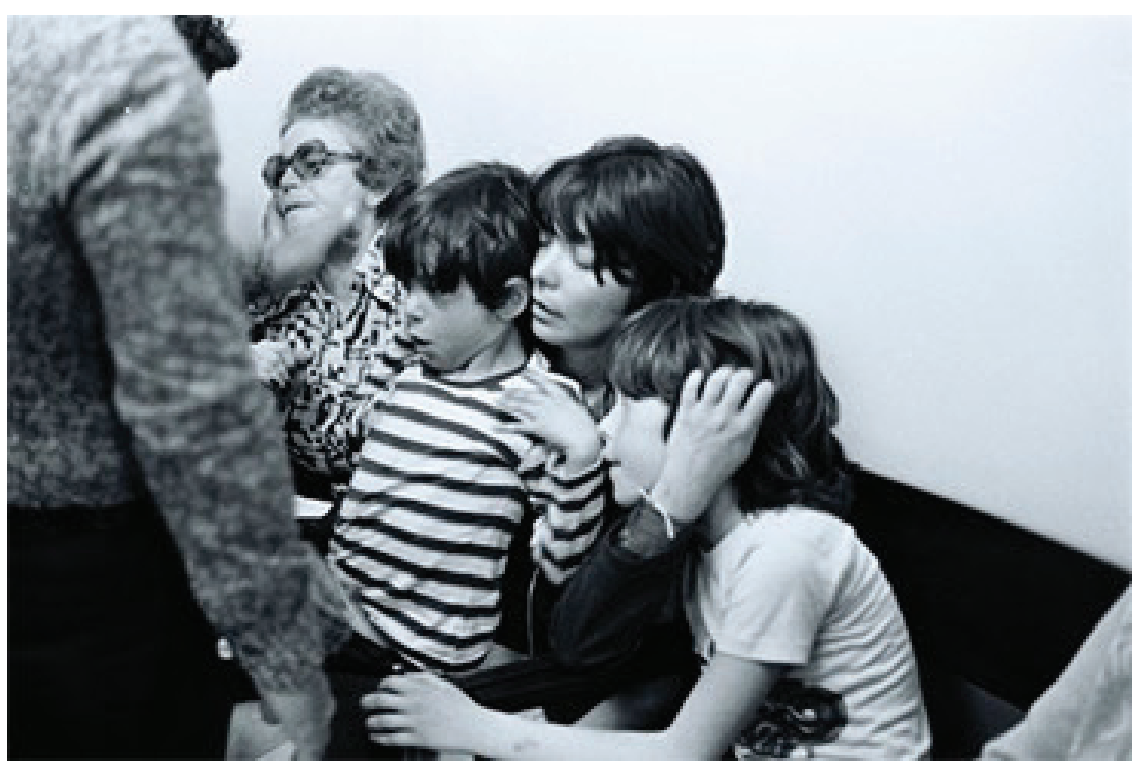

[Figura 03]

Rosa Gauditano. Greve, Estádio Vila Euclides, São Bernardo do campo.

1980.

Disponível em:<https://revistazum.com.br/ radar/rosa-gauditano-greves-abc/> Acesso em: 15 de outubro de 2019.

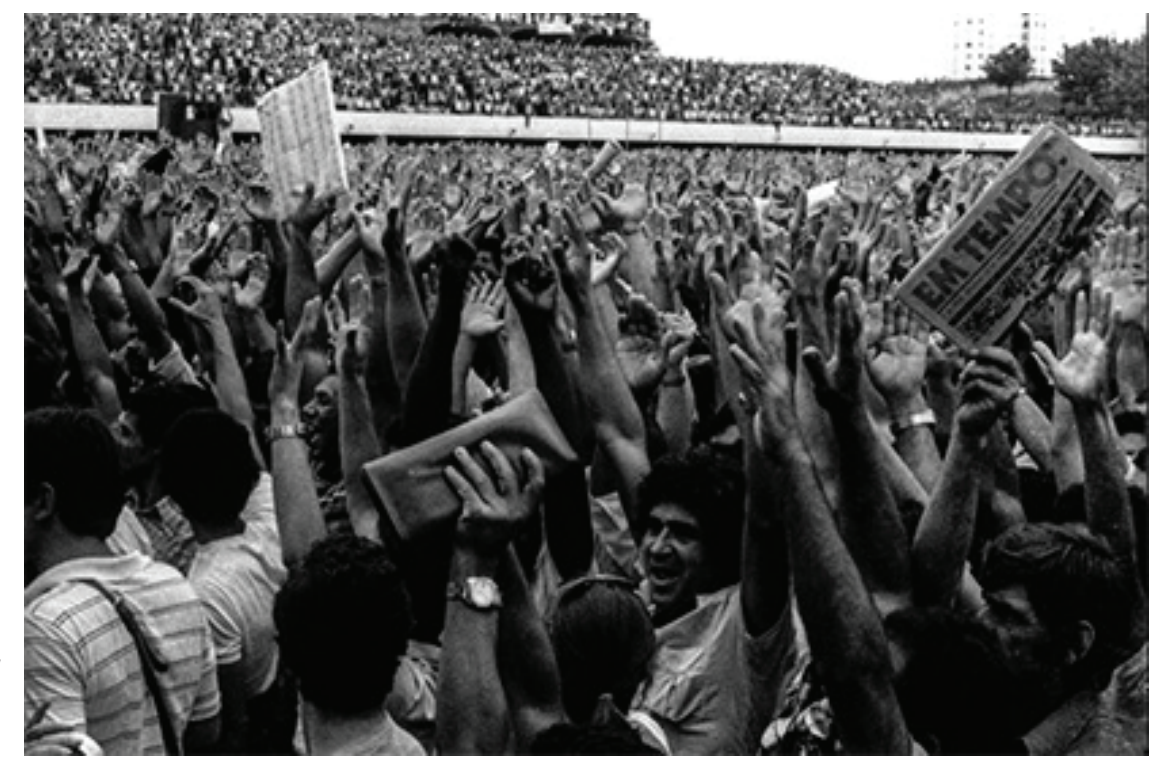


[Figura 04]

Rosa Gauditano. Movimento do Custo de Vida (MCV), também conhecido como Movimento Contra a Carestia.

1978.

Disponível em:<http://www.studiorimagens. com.br/index.asp?opc=exposicao_detaIhe\&exp=4> Acesso em: 16 de outubro de 2019.

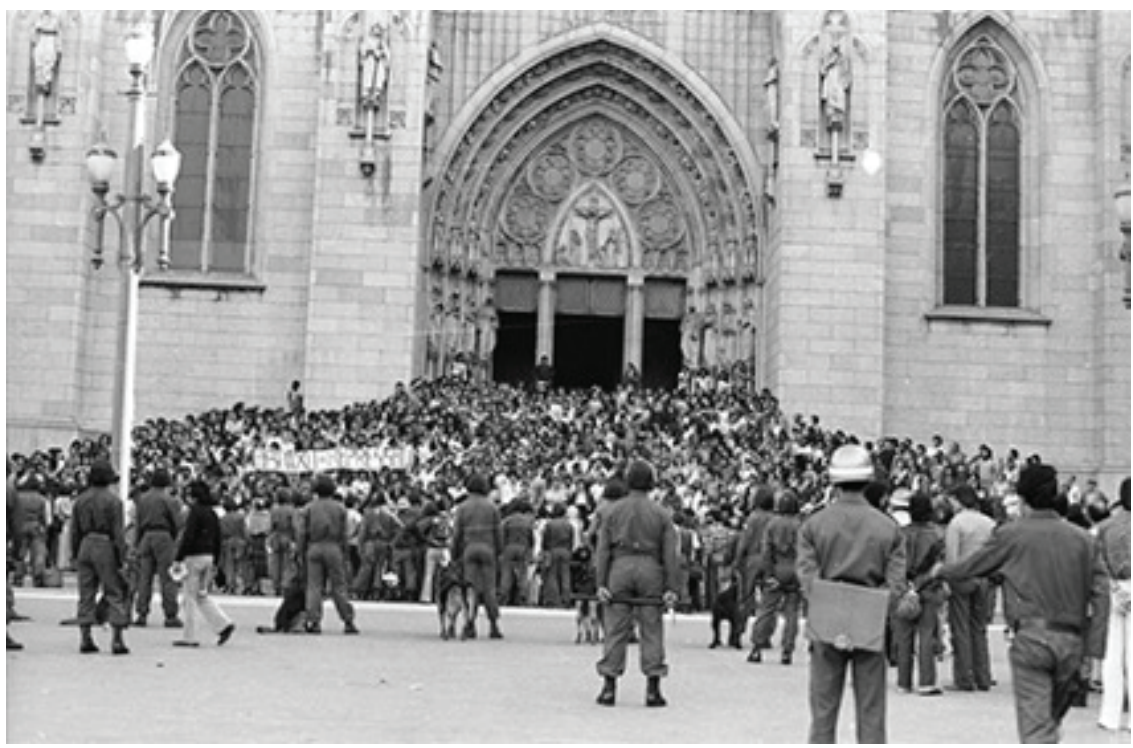

[Figura 05]

Rosa Gauditano. S.O.S Mulher, Praça da S. 1981.

Disponível em:<https://revistazum.com.br/ radar/rosa-gauditano-greves-abc/> Acesso em: 16 de outubro de 2019

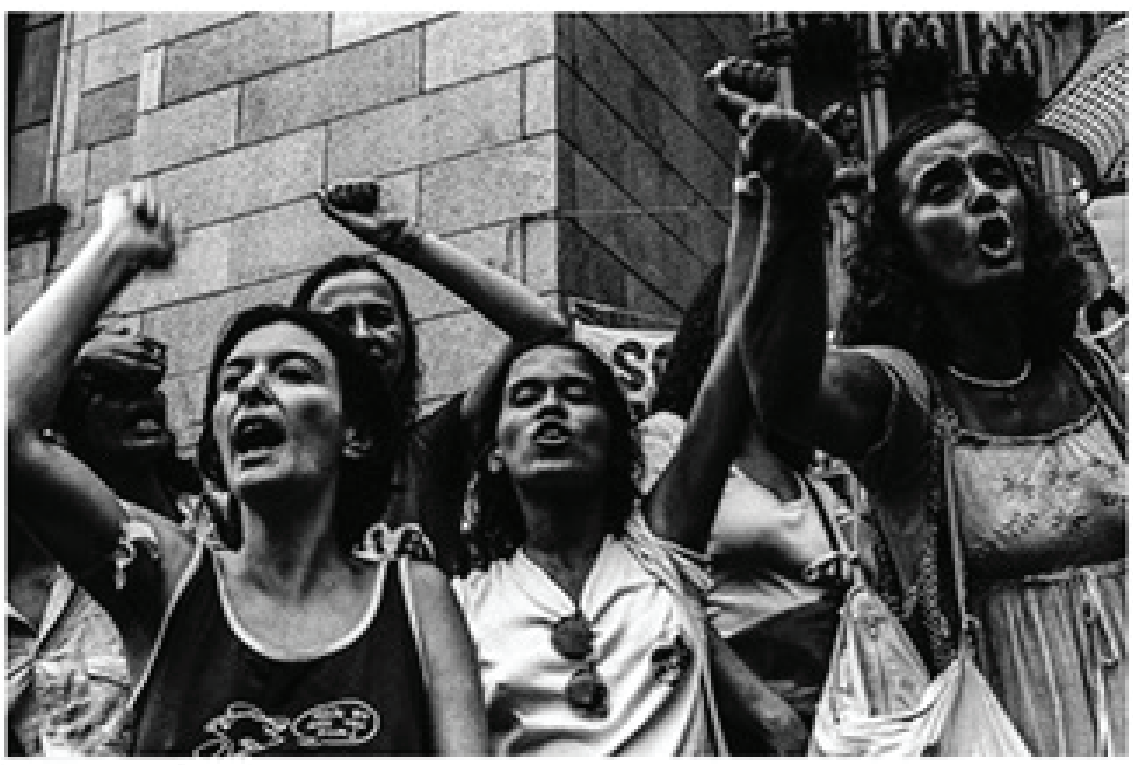

[Figura 06]

Nair Benedicto. Linha de frente do comício no centro de São Paulo, seguindo o cortejo fúnebre do operário Santo Dias. 1979.

Disponível em :< http://wrongwrong.net/ article/the-1978-81-strikes-in-brazil-throughthe-lenses-of-two-female-photographers-nair -benedicto-and-rosa-gauditano> Acesso em: 04 de abril de 2019.

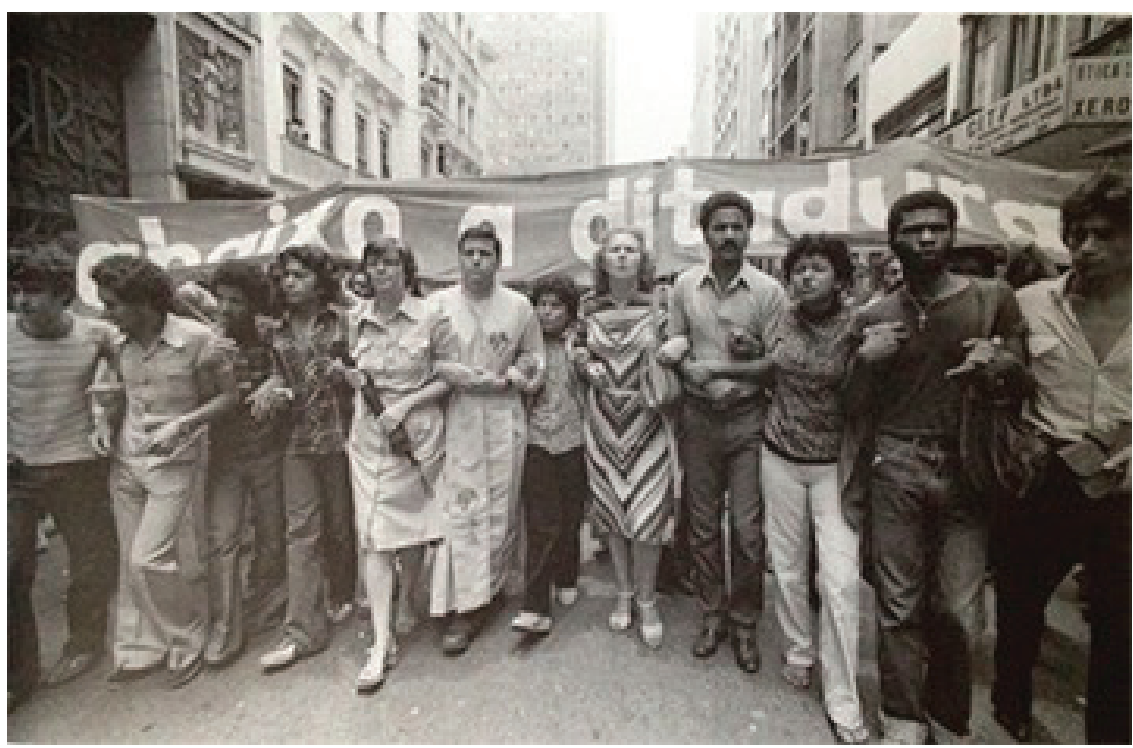


A figura 3 foi produzida no período que o Al-5 já tinha sido extinto. A fotógrafa captura o momento que os trabalhadores provavelmente estavam votando por melhores condições. Neste período, já havia maior liberdade para as classes populares se organizarem em espaços públicos, contudo a cautela era necessária. O olhar atento de Gauditano capturou um deles segurando firmemente o jornal Em tempo (figura 03), no intuito de mostrar para os leitores referencia à causa que os mobilizava. Zerwes ressalta que, a escolha da fotógrafa objetivou abranger "além do espaço público real onde acontecia a mobilização operária, o estádio de São Bernardo, também o novo espaço público de debates aberto pela imprensa alternativa" ${ }^{11}$.

Na figura 4 quando Gauditano registrou o Movimento do Custo de Vida, é possível detectar a escolha do posicionamento da sua câmera: de frente para os grevistas, possivelmente em um plano mais elevado, no qual conseguiu capturar o momento em que os militares pareciam estar preparados para acuar a multidão, enquanto o povo tinha nas mãos apenas uma faixa com os dizeres "abaixo a repressão" (figura 04).

Segundo Herbert ${ }^{12}$ o Movimento do Custo de Vida possuía três reivindicações centrais: "congelamento dos preços dos gêneros de primeira necessidade, concessão de um abono salarial de $20 \%$ para todos os trabalhadores e aumento salariais acima do custo de vida". Os trabalhadores estavam solicitando apenas uma condição digna de vida diante de um contexto social que achatava os salários em razão da alta da inflação.

Gauditano estava engajada com aqueles que vinham de um histórico de opressão. A fotojornalista também registrou os movimentos de mulheres - nem todos eram comprometidos com as pautas do movimento feministas, contudo, representavam a força que as mulheres estavam adquirindo na esfera pública e privada.

As mulheres registradas por Gauditano (figura 05) clamavam pelo direito de permaneceram vivas. As fotografadas estavam exigindo o fim da violência contra a mulher. Essa marcha foi organizada após a compositora e cantora Eliane de Grammont ter sido assassinada pelo seu ex-marido, em 1981. Ainda sob o temor de atos de repressão, as mulheres saíram às ruas de São Paulo, pedindo o direito de permaneceram donas de suas vivas e de seus desejos. Pertinente ressaltar ainda que, apesar de Rosa Gauditano ter fotografado movimentos de mulheres e mobilizações feministas, não há indícios de suas obras terem sido publicadas nos periódicos feministas alternativos da época. 
Mas, sim nos jornais alternativos de esquerda.

Nair Benedicto foi outro nome importante para o fotojornalismo naquela conjuntura. Documentou as mobilizações feministas, os movimentos de mulheres, as greves do ABC e tantas outras causas que necessitavam de visibilidade. Em uma entrevista concedida a Zerwes em 2018, Benedicto relata:

Eu acho que fazer política não é defender um partido, é defender um modo de vida, uma forma de ver a mulher, uma forma de ser mulher. Não importa se estou fotografando índio, se estou fotografando operário, ou se estou fotografando puta. O que importa é o que eu penso, como eu me coloco como mulher. Tem gente que acha que sou politizada demais. Dizem que politizo tudo. Mas não sou eu que politizo, a vida que é politizada. ${ }^{13}$

Benedicto foi presa política entre 1969 e 1970, passou nove meses no Departamento de Ordem Política e Social (DOPS) na cidade de São Paulo ${ }^{14}$. Após sair da prisão a fotografia entrou em sua vida como uma forma de resistência e luta. Foi das poucas fotojornalistas a registrar os movimentos populares em espaços públicos durante a ditadura militar, principalmente aqueles nos quais a presença das mulheres era marcante. Sobre o processo de fotografar mulheres, a fotógrafa explana: "Acho que o olhar feminino obrigatoriamente traz um universo que não é o universo masculino, é mais amplo, da vida mesmo. E quando a gente fotografa uma mulher, podemos nos enxergar na outra. Eu vejo isso" ${ }^{15}$.

O olhar empático e comprometido da fotojornalista capturou a força das mulheres no processo de resistência diante do regime ditatorial. Importante salientar que atuou no período efervescente da segunda onda do movimento feminista, fato que possivelmente reverberou na sua criação imagética. Benedicto olhou para outras mulheres e capturou desde cenas tensas às mais sensibilizadoras, mas sem abandonar os aspectos estéticos e o tom de crítica social.

Zerwes (2018) aponta que a imprensa nanica possibilitou a criação de novos espaços para a produção fotojornalística. Os novos ambientes alternativos contribuíram para a produção da fotorreportagem engajada no período ditatorial e a atuação das fotojornalistas mencionadas nos parágrafos anteriores intensificou e marcou a identidade imagética daquela conjuntura. Comprometi-

\footnotetext{
13 BENEDICTO, Nair. Sobre mulheres e fotografia: uma conversa com Nair Benedicto. Entrevista a Erica Zerwes. Revista de Fotografia ZUM. 2018. Disponível em:< https://revistazum.com.br/entrevistas/conversa-nair-benedicto/> Acesso em: 30 de outubro de 2019. 14 BENEDICTO, Nair. Tinha tudo para dar errado! Por sorte, deu tudo certo. Entrevista a Paulo Cesar Boni. Revista Discursos Fotográficos. Londrina, v.9, n.15, p. 243-262. 2013. Disponível em: http://www.uel.br/revistas/uel/index.php/discursosfotograficos/article/viewFile/16890/pdf_11 Acesso em: 20 de março de 2019. 15 Idem.
} 
das em denunciar o horror que foi a ditadura brasileira e o fortalecimento feminista, conseguiram contribuir significativamente na luta pela redemocratização do país.

\section{Referências bibliográficas}

ARAÚJO, Maria Paula Nascimento. A utopia fragmentada: as novas esquerdas no Brasil e no mundo na década de 1970. Rio De Janeiro: Ed. FGV, 2000.

BENEDICTO, Nair. Tinha tudo para dar errado! Por sorte, deu tudo certo. Entrevista a Paulo Cesar Boni. Revista Discursos Fotográficos. Londrina, v.9, n.15, p. 243-262. 2013. Disponível em: http://www.uel.br/revistas/uel/index.php/ discursosfotograficos/article/viewFile/16890/pdf_11 Acesso em: 20 de março de 2019.

CHAUI, Marilena. Sobre a violência. Ericka Marie Itokazu, Luciana Chaui-Berlinck. (Orgs). Belo Horizonte: Autentica Editora. 2017.

DIDI-HUBERMAN, Georges. Devolver uma imagem. In: ALLOA, Emmanuel (Org.). Pensar a imagem. Belo Horizonte: Autêntica, 2015, pp. 205-225.

HABERT, Nadine. A década de 70: apogeu e crise da ditadura militar brasileira. São Paulo: Editora Ática, 1992.

INSTITUTO VLADIMIR HERZOC. Edição fac-similar do jornal Ex realizada nas oficinas gráficas da Imprensa Oficial do Estado de São Paulo. 2010.

KUCINSKI, Bernardo. Jornalistas e revolucionários nos tempos da imprensa alternativa. São Paulo: Scritta, 1991.

PINTO, Celi Regina Jardim. Feminismo, história e poder. Rev. Sociol. Política, v. 18, n. 36, p. 15-23, jun. Curitiba 2010. Disponível em:< http://www.scielo.br/pdf/rsocp/v18n36/03.pdf> Acesso em: 15 de outubro de 2018.

. Uma história do feminismo no Brasil. São Paulo: Editora Fundação Perseu Abramo. 2003.

SARTI, Cyntia Andersen. O feminismo brasileiro desde os anos 1970: revisitando uma trajetória. Estudos Feministas, Florianópolis, maio-agosto/2004. Disponível em:< http://www.scielo.br/pdf/ref/v12n2/23959.pdf> Acesso em: 6 de março de 2019.

ZERWES, Erika. As fotografias de Rosa Cauditano e as greves do ABC no final dos anos 1970. Reportagem para Revista de Fotografia ZUM. 2018. Disponível em:<https://revistazum.com.br/radar/rosa-gauditano-greves-abc/>Acesso em: 15 de outubro de 2019. 